\title{
Factors Affecting Adverse Drug Reaction Reporting of Healthcare Professionals and Their Knowledge, Attitude, and Practice towards ADR Reporting in Nekemte Town, West Ethiopia
}

\author{
Lense Temesgen Gurmesa ${ }^{1}$ and Mohammed Gebre Dedefo ${ }^{2}$ \\ ${ }^{1}$ Nekemte Health Center, Oromia, Ethiopia \\ ${ }^{2}$ Department of Pharmacy, Wollega University, Oromia, Ethiopia \\ Correspondence should be addressed to Mohammed Gebre Dedefo; mohamedg@wollegauniversity.edu.et
}

Received 31 August 2016; Accepted 20 October 2016

Academic Editor: Kumud K. Kafle

Copyright (C) 2016 L. T. Gurmesa and M. G. Dedefo. This is an open access article distributed under the Creative Commons Attribution License, which permits unrestricted use, distribution, and reproduction in any medium, provided the original work is properly cited.

\begin{abstract}
Background. Adverse drug reactions are global problems of major concern. Adverse drug reaction reporting helps the drug monitoring system to detect the unwanted effects of those drugs which are already in the market. Aims. To assess the knowledge, attitude, and practice of health care professionals working in Nekemte town towards adverse drug reaction reporting. Methods and Materials. A cross-sectional study design was conducted on a total of 133 health care professionals by interview to assess their knowledge, attitude, and practice using structured questionnaire. Results. Of the total respondents, only 64 (48.2\%), 56 (42.1\%), and $13(9.8 \%)$ health care professionals have correctly answered the knowledge, attitude, and practice assessment questions, respectively. Lack of awareness and knowledge on what, when, and to whom to report adverse drug reactions and lack of commitments of health care professionals were identified as the major discouraging factors against adverse drug reaction reporting. Conclusion. This study has revealed that the knowledge, attitude, and practice of the health care professionals working in Nekemte town towards spontaneous adverse drug reaction reporting were low that we would like to recommend the concerned bodies to strive on the improvement of the knowledge, attitude, and practice status of health care professionals.
\end{abstract}

\section{Introduction}

Adverse drug reactions (ADRs) are global problems of major concern. They affect both children and adults with varying magnitudes, causing both morbidity and mortality [1-3]. An $\mathrm{ADR}$ is defined by the world health organization (WHO) as "a noxious, unintended effect of a drug that occurs in doses normally used in humans for the diagnosis, prophylaxis and treatment of disease" [4].

The information collected during the premarketing phase is incomplete with regard to adverse drug reactions and this is mainly because (1) patients used in clinical trials are limited in number and are not representative to the public at large. In addition, the conditions of use of medicines differ from those in clinical practice and the duration is limited. (2) Information about rare but serious adverse reactions, chronic toxicity, and use in special groups (such as children, the elderly, or pregnant women) or drug interactions is often incomplete. Therefore, postmarketing surveillance is important to permit detection of less common but sometimes very serious ADRs. Thus, postmarketing surveillance is important to permit detection of less common, but sometimes very serious ADRs. Therefore health professionals worldwide should report on ADRs as it can save lives of their patients and others [5].

Different studies have documented that new adverse reaction are discovered efficiently from spontaneous reporting than from other methods, including large postmarketing studies $[3,5-8]$. The occurrences of ADRs depend on the age, 
sex, genetic, polypharmacy, dose accuracy, and environmental and other internal factors like disease conditions [9-20].

In Ethiopia, a report by Drug Administration and Control Authority (DACA), showed that out of the total of ADRs encountered (413) only 22 are reported to DACA making the total reported to be $5 \%$ only [12]. This shows that spontaneous reporting by health care professionals was very low. Other studies done in Ethiopia also suggested that awareness raising program on the ADR reporting system need to be designed to health professionals by relevant bodies and ADR reporting system need to be introduced to improve ADR reporting [911].

This study was aimed at investigating the knowledge, attitude, and practice of HCPs on spontaneous ADR reporting and factors affecting the reporting process in Nekemte town and also to suggest possible ways of improving method of reporting.

\section{Methods}

2.1. Study Setting and Period. Nekemte town is situated on a flat, hilly landscape. It is located at a distance of $331 \mathrm{~km}$ west of Addis Ababa, $110 \mathrm{~km}$ North East of Gimbi, the principal town of West Wollega Zone, and $250 \mathrm{~km}$ North West of Jima Zone in Oromia Regional state. According to the central statistical Agency of 2007, the population size of Nekemte is 75,219 [21]. The 2015 projected total population is estimated to be around 110,640 [22]. There are about 176 HCPs (clinical nurses, doctors, health officers, and pharmacists) working for health service in Nekemte town private and governmental health centers and clinics. The study was conducted from January 2015 to June 2015.

2.2. Study Design. Descriptive cross-sectional study design was conducted by using structure questionnaires.

2.3. Study Population. All the nurses, medical doctors, health officers, and pharmacists who are available during the study period and willing to participate in the study with equal chance were included.

2.4. Sample Size Determination. Sample size was calculated using single proportion of size less than 10,000 assuming the KAP of ADR-report to be $50 \%$; to get maximum possible size the following equation was used:

$$
S=\frac{z^{2} p q}{w},
$$

where $S$ is sample size, $z^{2}$ critical value equals $1.96, p$ is precision (marginal error) equal to $0.05, S=(1.96)^{2}(0.5) / 0.05^{2}$, and $S=384$

The total number of HCPs (nurses, medical doctors, health officers, and pharmacists) working in Nekemte town private and governmental health centers and clinics as well as in Nekemte hospital is found to be 176.

Since this figure is below 10,000 we use the following adjustment for the sample size:

$$
S=\frac{n}{1+n / N}
$$

where $n$ is sample size for population of size above 10,000 and $N$ is number of source populations. Therefore,

$$
S=\frac{384}{1+384 / 176}
$$

$S=121$; then by adding $10 \%$ to compensate nonrespondents, $S=133$.

2.5. Sampling Technique. Assuming variation among the different HCPs KAP towards ADR reporting, study subjects were recruited using stratified random sampling technique with proportional allocation:

medical doctors $(\mathrm{MDs})=25$; then the sample taken was $=25 / 176 * 133=19$;

nurses $=93$; then the sample taken was $=93 / 176 * 133$ $=70$;

health officers $(\mathrm{HOs})=33$; then the sample taken was $=33 / 176 * 133=25$;

pharmacists $=25$; then the sample taken was $=$ $25 / 176 * 133=19$

2.6. Data Collection Process. Data were collected by the researcher assistants under the supervision of principal investigators using structural questionnaires on the sociodemographic status, the knowledge, attitude, and practice of health professional towards ADR reporting, and influencing factors.

2.7. Data Analysis and Interpretation. After data collection, data were entered into the Statistical Package for the Social Sciences (SPSS) version 20 for analysis. Checking, clearing, and coding of data were done before the analysis activities. Data collection from interviewee was analyzed, summarized, and represented in tables. By the analyzing data the KAP of HCPs towards ADR reporting and factors affecting the reporting process was assessed.

2.8. Ethical Consideration. Ethical clearance was obtained from the Ethical Review Committee of Wollega University, College of Medical and Health Sciences. A participant's written informed consent was obtained after explaining about the purpose and procedures of the study. In addition all the responses were kept confidential.

\section{Results}

This study was conducted on 133 health professionals comprising medical doctors, pharmacists, health officers, and nurses.

3.1. Sociodemographic Features. Of the total 133 HCPs, 90 $(67.6 \%)$ were males and $43(32.3 \%)$ were females. The majority of participants $98(73.6 \%)$ were below 36 years. The majority of HCPs $50(37.6 \%)$ have 3-5 years of service. The study included 70 (52.6\%) nurses, 19 (14.3\%) MDs, 19 (14.3\%) pharmacists, and 25 (18.8\%) HOs (Table 1). 
TABLE 1: The sociodemographic status of respondents in Nekemte town from January 2015 to June 2015.

\begin{tabular}{lccc}
\hline Variable & Category & Frequency & $\%$ \\
\hline \multirow{4}{*}{ Age } & $<26$ & 51 & 38.3 \\
& $26-35$ & 47 & 35.3 \\
& $36-45$ & 27 & 20.3 \\
Sex & $>45$ & 8 & 6.0 \\
\hline \multirow{4}{*}{ Profession } & Male & 90 & 67.6 \\
& Female & 43 & 32.3 \\
\hline \multirow{4}{*}{ Year of service } & MD & 19 & 14.3 \\
& Pharmacist & 19 & 14.3 \\
& Nurse & 70 & 52.6 \\
& Health officer & 25 & 18.8 \\
\hline
\end{tabular}

3.2. KAP of Health Care Professionals. Regarding the knowledge of HCPs, 83 (62.4\%) had heard about ADR reporting. Out of 83 HCPs who heard about ADR reporting, 37 (44.5\%) get information about ADR reporting from formal teaching. Only 31 (37.4\%) HCPs had heard about the existence of yellow card. Only 20 (24.0\%) HCPs said that ADR had to be reported to Food, Medicine and Healthcare Administration and Control Authority of Ethiopia (FMHACA) (Table 2).

Regarding attitude of the HCPs, the majority of them (103 (77.4\%)) agree that ADR reporting is essential and out of 103 HCPs 58 (43.6\%) suggested that ADR reporting is encouraged when reaction is serious. Of the respondents $63(47.5 \%)$ responded that premarket drug evaluation is not enough for detecting ADR. Most of the HCPs (77 (57.9\%)) said that ADR reporting must be compulsory (Table 3).

Regarding practice of HCPs, only 36 (27\%) HCPs had faced patients with ADR. From those 36 HCPs who have noticed ADRs from their clients, 14 (38.8\%) have reported ADR; 11 (78.5\%) had reported 1 to 3 times; and 3 (21.4\%) did more than 3 times. On the reasons why HCPs did not report ADRs (i.e., from those 22), 10 (45.5\%) were not aware whether to report them, $9(40.9 \%)$ because there was no report available at the work places, and 2 (9\%) do not know the system responsible for receiving their reports. Types of ADRs which were reported by 14 respondents are unexpected $(5,35.7 \%)$, serious $(6,42.8 \%)$, reactions to recently marketed (within five years) pharmaceuticals $(2,14.4 \%$ ), and all of the three types $(1,7.1 \%)$. ADRs were reported mainly to the responsible bodies in the respective health center/hospital 7 (50.0\%), to DTC 5 (35.7\%), and FMHACA 2 (14.3\%) (Table 4).

When we see the comparison of the KAP status of HCPs in the four professions, from the total of $20 \mathrm{KAP}$ based questions interviewed, 9 (45\%) were knowledge based, $5(25 \%)$ attitudinal, and the remaining $6(30 \%)$ practice oriented. Of the total respondents, only 64 (48.2\%), 56 (42.1\%), and $13(9.8 \%)$ health care professionals have correctly
TABLE 2: The knowledge status data of HCPs on ADR reporting in Nekemte town from January 2015 to June 2015.

\begin{tabular}{|c|c|c|c|}
\hline Variable & Category & Frequency & $\%$ \\
\hline \multirow{2}{*}{$\begin{array}{l}\text { Heard about } \\
\text { ADR-reporting }\end{array}$} & Yes & 83 & 62.4 \\
\hline & No & 50 & 37.6 \\
\hline \multirow{5}{*}{ Information source } & In-service training & 24 & 27.6 \\
\hline & Mass media & 6 & 7.2 \\
\hline & Journals or publication & 9 & 10.8 \\
\hline & Formal teaching & 37 & 44.5 \\
\hline & Peer group & 7 & 8.4 \\
\hline \multirow{3}{*}{$\begin{array}{l}\text { ADRs can be reported } \\
\text { on }\end{array}$} & Drugs & 43 & 51.8 \\
\hline & Medical devices & 12 & 14.4 \\
\hline & Both & 28 & 33.7 \\
\hline \multirow{2}{*}{$\begin{array}{l}\text { Know about existence } \\
\text { of yellow card }\end{array}$} & Yes & 31 & 37.4 \\
\hline & No & 52 & 62.6 \\
\hline \multirow{7}{*}{$\begin{array}{l}\text { Agents to which ADR } \\
\text { is to be reported }\end{array}$} & I do not know & 28 & 33.7 \\
\hline & FMHACA & 20 & 24.0 \\
\hline & Health center & 14 & 16.8 \\
\hline & DTC/local drug monitor & 9 & 10.7 \\
\hline & $\mathrm{MD} /$ physician & 6 & 7.2 \\
\hline & Manufacturer & 3 & 3.6 \\
\hline & $\begin{array}{c}\text { Department of } \\
\text { Pharmacy }\end{array}$ & 3 & 3.6 \\
\hline \multirow{2}{*}{$\begin{array}{l}\text { Know responsible } \\
\text { body }\end{array}$} & Yes & 41 & 30.8 \\
\hline & No & 92 & 69.1 \\
\hline \multirow{3}{*}{$\begin{array}{l}\text { To which drug do you } \\
\text { expect more } \\
\text { unexpected ADRs? }\end{array}$} & Newly marketed drugs & 87 & 65.4 \\
\hline & Established drugs & 14 & 10.5 \\
\hline & I do not know & 32 & 24.0 \\
\hline \multirow{5}{*}{$\begin{array}{l}\text { ADRs that should be } \\
\text { reported }\end{array}$} & All suspected reactions & 20 & 15.0 \\
\hline & Unknown/unexpected & 33 & 24.8 \\
\hline & Serious & 40 & 30.1 \\
\hline & $\begin{array}{l}\text { Unexpected therapeutic } \\
\text { effects }\end{array}$ & 21 & 15.7 \\
\hline & All & 19 & 13.2 \\
\hline \multirow{3}{*}{$\begin{array}{l}\text { Mostly expected to be } \\
\text { reported }\end{array}$} & Expected/labeled & 45 & 33.8 \\
\hline & Unexpected/unlabeled & 54 & 40.6 \\
\hline & I do not know & 34 & 25.5 \\
\hline
\end{tabular}

answered the knowledge, attitude, and practice assessment questions, respectively (Table 5).

\subsection{Factors That Affect Spontaneous ADR Reporting}

3.3.1. Discouraging Factor. As shown in Table 6, HCPs suggested the factors negatively affecting the ADR reporting process. Lack of awareness and knowledge on what, when, and to whom to report ADRs was 41 (30.8\%) of the respondents followed by lack of commitments of HCPs constituting 34 (25.5\%).

3.3.2. Encouraging Factors. Factors responded by HCPs to improve ADR reporting as shown in Table 6 are awareness 
TABLE 3: Attitude of HCPs towards ADR-reporting in Nekemte town from January 2015 to June 2015.

\begin{tabular}{lccc}
\hline Variable & Category & Frequency & $\%$ \\
\hline ADR-reporting & Agree & 103 & 77.4 \\
essential & Disagree & 6 & 4.5 \\
& Neutral & 24 & 18.1 \\
\hline \multirow{4}{*}{ Reporting } & Reaction is serious & 58 & 43.6 \\
encouraged when & Unusual reaction & 33 & 24.8 \\
& You are certain & 31 & 23.3 \\
& Every one of each & 11 & 8.3 \\
\hline \multirow{2}{*}{ Premarket drug } & Yes & 21 & 15.7 \\
evaluation enough & No & 63 & 47.5 \\
& Neutral & 49 & 36.8 \\
\hline \multirow{2}{*}{ Yellow card reporting } & Yes & 46 & 34.8 \\
cost effective & No & 13 & 9.8 \\
& Neutral & 74 & 55.6 \\
\hline \multirow{3}{*}{ ADR reporting } & Compulsory & 77 & 57.9 \\
& Voluntary & 38 & 28.6 \\
& Neutral & 18 & 13.5 \\
\hline
\end{tabular}

TABLE 4: Practice of HCPs on ADR-reporting in Nekemte town from January 2015 to June 2015.

\begin{tabular}{|c|c|c|c|}
\hline Variable & Category & Frequency & $\%$ \\
\hline \multirow{2}{*}{$\begin{array}{l}\text { Faced ADR from } \\
\text { patient/s/ }\end{array}$} & Yes & 36 & 27.0 \\
\hline & No & 97 & 73.0 \\
\hline \multirow{2}{*}{ Reported } & Yes & 14 & 38.8 \\
\hline & No & 22 & 61.1 \\
\hline \multirow{2}{*}{$\begin{array}{l}\text { Number of } \\
\text { ADR-reports done }\end{array}$} & 1-3 times & 11 & 78.5 \\
\hline & More than 3 times & 3 & 21.4 \\
\hline \multirow{4}{*}{ Reason not to report } & I did not know & 10 & 45.5 \\
\hline & No report form & 9 & 40.9 \\
\hline & No system responsible & 2 & 9.1 \\
\hline & Not usual to report & 1 & 4.5 \\
\hline \multirow{4}{*}{$\begin{array}{l}\text { Types of } \\
\text { ADRs-reported }\end{array}$} & Unexpected & 5 & 35.7 \\
\hline & Serious & 6 & 42.7 \\
\hline & $\begin{array}{l}\text { Reaction to recently } \\
\text { marketed }\end{array}$ & 2 & 14.2 \\
\hline & All of the above & 1 & 7.1 \\
\hline \multirow{3}{*}{$\begin{array}{l}\text { Agents to whom ADRs } \\
\text { were reported }\end{array}$} & FMHACA & 2 & 14.3 \\
\hline & DTC & 5 & 35.7 \\
\hline & $\begin{array}{l}\text { Other responsible } \\
\text { bodies }\end{array}$ & 7 & 50.0 \\
\hline
\end{tabular}

creation on what, when, and to whom to report ADRs accounting for 56 (42.1\%) followed by in-service training 35 $(26.3 \%)$.

\section{Discussion}

The result of our finding showed that the knowledge of HCPs about ADR reporting is low with only 64 (48.2\%) of the HCPs having answered correctly to the knowledge based questions. This result is consistent with different studies; only $34.2 \%$ of the respondents had sufficient knowledge on the ADR reporting system in a study conducted in Amhara Region of Ethiopia [11], 23.17\% in a study conducted at Southwest Ethiopia [9], 39.6\% in a study conducted in Saudi Arabia [16], and $39.4 \%$ in a study conducted in Nepal [17].

When we compare the knowledge of HCPs among themselves medical doctors (84.2\%) and pharmacists (84.2\%) were more knowledgeable than health officers (56\%) and nurses (25.7\%). This finding is consistent with a study reported from Nepal [17]. However studies from Nigeria [13] and Saudi Arabia [16] reported that pharmacists are more knowledgeable than medical doctors and nurses. This shows that there is a knowledge variation between the different health care professionals on spontaneous ADR reporting which could be because of difference in access to information about ADR reporting.

Concerning the attitude of HCPs, only 56 (42.1\%) HCPs have correctly answered the attitude based questions. The finding of this study showed that there is low attitude towards reporting ADR as compared to the previously done studies which showed high attitude towards ADR reporting: $75 \%$ in Southwest Ethiopia [9], 60\% in Amhara Region of Ethiopia [11], 73.4\% in different hospitals of Ethiopia [12], 66.3\% in Nepal [17], and $82.2 \%$ in South India [20]. The difference could be because of lack of training, unawareness regarding the ADR reporting form, and lack of commitments of HCPs in West Wollega.

When we compare the attitude of HCPs among themselves pharmacists (89.5\%) have good attitude towards ADR reporting followed by medical doctors (73.6\%). Nurses have the poorest attitude in which only $20 \%$ have good attitude. This finding is consistent with a study reported from Southwest Ethiopia [9], Nigeria [13], and Nepal [17].

Regarding the practice of HCPs, this study revealed that the practice of HCPs towards ADR reporting is poor with only $13(9.8 \%)$ of HCPs having answered correctly to the practice based questions. The practice of HCPs in this study is lower than other studies: $16.2 \%$ in Amhara Region of Ethiopia [11], $13.8 \%$ in different hospitals of Ethiopia [12], 33.7\% in Nepal [17], and 22.8\% in South India [20].

This study identified the factors that discourage the spontaneous ADR reporting of the HCPs; accordingly lack of awareness and knowledge on what, when, and to whom to report ADRs is the common factor followed by lack of commitments of HCPs and unavailable format. To overcome these discouraging factors HCPs have suggested some factors to improve ADR reporting; these are awareness creation on what, when, and to whom to report ADRs, in-service training, direct supervision of patients by pharmacist, and making report formats available are the main encouraging factors.

Strength of our study was that we have used a detailed structured questionnaire on KAP towards ADR reporting and the study subjects were recruited by using stratified random sampling technique with proportional allocation. 
TABLE 5: Comparison of the KAP of HCPs in each health profession in Nekemte town from January 2015 to June 2015.

\begin{tabular}{|c|c|c|c|c|c|c|c|}
\hline \multirow[t]{2}{*}{ Profession } & \multirow[t]{2}{*}{$\begin{array}{c}\text { Number of } \\
\text { professionals }\end{array}$} & \multicolumn{2}{|c|}{$\begin{array}{c}\text { Knowledge } \\
(9,45 \% \text { of total KAP questions })\end{array}$} & \multicolumn{2}{|c|}{$\begin{array}{c}\text { Attitude } \\
(5,25 \% \text { of total KAP questions })\end{array}$} & \multicolumn{2}{|c|}{$\begin{array}{c}\text { Practice } \\
(6,30 \% \text { of total KAP questions }\end{array}$} \\
\hline & & Frequency & $\%$ & Frequency & $\%$ & Frequency & $\%$ \\
\hline Nurse & 70 & 18 & 25.7 & 14 & 20.0 & 7 & 10.0 \\
\hline Doctor & 19 & 16 & 84.2 & 14 & 73.6 & 2 & 10.5 \\
\hline $\begin{array}{l}\text { Health } \\
\text { officer }\end{array}$ & 25 & 14 & 56.0 & 11 & 44.0 & 1 & 4.0 \\
\hline Pharmacist & 19 & 16 & 84.2 & 17 & 89.5 & 3 & 15.8 \\
\hline Total & 133 & 64 & 48.2 & 56 & 42.1 & 13 & 9.8 \\
\hline $\begin{array}{l}\text { General } \\
\text { assessment }\end{array}$ & & \multicolumn{2}{|c|}{ Low knowledge } & \multicolumn{2}{|c|}{ Low attitude } & \multicolumn{2}{|c|}{ Low practice } \\
\hline
\end{tabular}

TABLE 6: Factors that affect spontaneous ADR-reporting in Nekemte town from January 2015 to June 2015.

\begin{tabular}{lcc}
\hline Variables & Frequency & $\%$ \\
\hline $\begin{array}{l}\text { Discouraging factors } \\
\text { Lack of awareness and knowledge on what, }\end{array}$ & 41 & 30.8 \\
when, and to whom to report & 22 & 16.5 \\
Unavailable format & 18 & 13.5 \\
Not knowing or absence of responsible body & 34 & 25.5 \\
Lack of commitment of HCPs & 12 & 9.0 \\
Low patient follow-up/contact & 6 & 4.5 \\
$\begin{array}{l}\text { I cannot suggest } \\
\text { Encouraging factors }\end{array}$ & \\
$\begin{array}{l}\text { Awareness creation on what, when, how, \& to } \\
\text { whom to report and increasing awareness at all }\end{array}$ & 56 & 42.1 \\
levels of education & 35 & 26.3 \\
$\begin{array}{l}\text { In-service training } \\
\text { Make availability of the reports format }\end{array}$ & 14 & 10.5 \\
$\begin{array}{l}\text { Announcing ADR report as it is a professional } \\
\text { obligation of HCPs }\end{array}$ & 8 & 6.0 \\
$\begin{array}{l}\text { Follow-up of patients } \\
\text { Direct supervision of patients by pharmacist }\end{array}$ & 9 & 6.7 \\
\hline
\end{tabular}

The limitation of this study was that this study did not show the KAP difference of health care professionals within the same profession with different level of education.

\section{Conclusion}

The finding of this study showed that the knowledge, attitude, and practice of the HCPs working in Nekemte town towards spontaneous ADR reporting were low. Thus, we would like to recommend the concerned bodies to strive on the improvement of the knowledge, attitude, and practice status of health care professionals.

\section{Competing Interests}

The authors declare that they have no competing interests.

\section{Acknowledgments}

The authors are thankful to Wollega University for their unreserved cooperation in making this study a fruitful work. They are also thankful for data collectors and the study participants.

\section{References}

[1] C. George, V. Nathanson, C. Seddon et al., "Reporting adverse drug reactions: a guide for healthcare professionals," BMA Board of Science, 2006.

[2] T. Kurokawa, A. M. Correa-Nunes, A. Czarnecki et al., Safety Monitoring of Medicinal Products: Guidelines for Setting up and Running a Pharmacovigilance Centre, The Uppsala Monitoring Centre (the UMC), WHO Collaborating Centre for International Drug Monitoring, 2000.

[3] A. R. Abubakar, N. B. Simbak, and M. Haque, "A systematic review of knowledge, attitude and practice on adverse drug reactions and pharmacovigilance among doctors," Journal of Applied Pharmaceutical Science, vol. 4, no. 10, pp. 117-127, 2014.

[4] World Health Organization, "International drug monitoring: the role of national centers," Technical Report Series 498, World Health Organization, Geneva, Switzerland, 1972.

[5] Guidelines for Detecting \& Reporting Adverse Drug Reactions: Individual Case Safety Reports for Healthcare Professionals, Rational Drug Use and Pharmacovigilance DepartmentJFDA, 2014.

[6] World Alliance for Patient Safety, WHO Draft Guidelines for Adverse Event Reporting and Learning Systems: From Information to Action, World Health Organization, Geneva, Switzerland, 2005.

[7] C. Ishiguro, M. Hall, G. A. Neyarapally, and G. Dal Pan, "Post-market drug safety evidence sources: an analysis of FDA drug safety communications," Pharmacoepidemiology and Drug Safety, vol. 21, no. 10, pp. 1134-1136, 2012.

[8] B. C. Stricker and B. M. Psaty, "Detection, verification, and quantification of adverse drug reactions," British Medical Journal, vol. 329, no. 7456, pp. 44-47, 2004.

[9] M. T. Angamo, A. Tesfa, and N. T. Wabe, "Knowledge, attitude and practice of adverse drug reaction reporting among health professionals in southwest Ethiopia," TAF Preventive Medicine Bulletin, vol. 11, no. 4, pp. 397-406, 2012. 
[10] C. Teshale and R. Melaku, "Attitude and practice of health professioals towards Adverse Drug Reaction (ADR) reporting in jimma zone hospitals, South West Ethiopia," Pharmacologyonline, vol. 2, pp. 308-315, 2010.

[11] W. N. Mulatu and A. Worku, "Assessment of knowledge, attitude and practice of health professionals towards adverse drug reaction reporting and factors associated with reporting," Journal of Pharmacovigilance, vol. 2, no. 4, 2014.

[12] "Report on the assessment of health care providers' knowledge, attitude and practice on Adverse Drug Reaction (ADR) reporting and its monitoring: Drug Administration and Control Authority in collaboration with MSH/RPM plus/SPS," 2008.

[13] J. O. Fadare, O. O. Enwere, A. O. Afolabi, B. A. Z. Chedi, and A. Musa, "Knowledge, attitude and practice of adverse drug reaction reporting among healthcare workers in a tertiary centre in Northern Nigeria," Tropical Journal of Pharmaceutical Research, vol. 10, no. 3, pp. 235-242, 2011.

[14] N. N. Kamal, E. G. Kamel, and E. M. Mahfouz, "Adverse drug reactions reporting, knowledge, attitude and practice of physicians towards it in El Minia University Hospitals," International Public Health Forum, vol. 1, no. 4, pp. 13-17, 2014.

[15] B. Kozamernik, "Spontaneous adverse drug reaction reporting: attitudes and practice of health care professionals and distributors in South East European region," Farmacevtski Vestnik, vol. 61, no. 5-6, pp. 271-281, 2010.

[16] M. M. M. Abdel-Latif and B. A. Abdel-Wahab, "Knowledge and awareness of adverse drug reactions and pharmacovigilance practices among healthcare professionals in Al-Madinah AlMunawwarah, Kingdom of Saudi Arabia," Saudi Pharmaceutical Journal, vol. 23, no. 2, pp. 154-161, 2015.

[17] S. Palaian, M. I. Ibrahim, and P. Mishra, "Health professionals' knowledge, attitude and practices towards pharmacovigilance in Nepal," Pharmacy Practice, vol. 9, no. 4, pp. 228-235, 2011.

[18] V. Bharadwaj, N. Budania, A. Mondal, V. Yadav, and P. Sharma, "A survey to assess the awareness of adverse drug reactions and pharmacovigilance practices among healthcare professionals in a tertiary care hospital," International Journal of Medical Research Professionals, vol. 2, no. 1, pp. 134-137, 2016.

[19] R. Agarwal, A. M. Daher, and N. M. Ismail, "Knowledge, practices and attitudes towards adverse drug reaction reporting by private practitioners from Klang Valley in Malaysia," Malaysian Journal of Medical Sciences, vol. 20, no. 2, pp. 52-61, 2013.

[20] S. K. Gupta, R. P. Nayak, R. Shivaranjani, and S. K. Vidyarthi, "A questionnaire study on the knowledge, attitude, and the practice of pharmacovigilance among the healthcare professionals in a teaching hospital in South India," Perspectives in Clinical Research, vol. 6, no. 1, pp. 45-52, 2015.

[21] The 2007 Population and Housing Census of Ethiopia: Statistical Report for Oromiya Region, 2007.

[22] https://www.quandl.com/data/CITYPOP/CITY_NEKEMTEORETHIOPIA. 


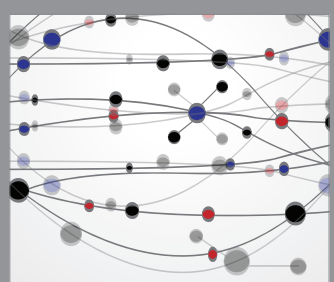

The Scientific World Journal
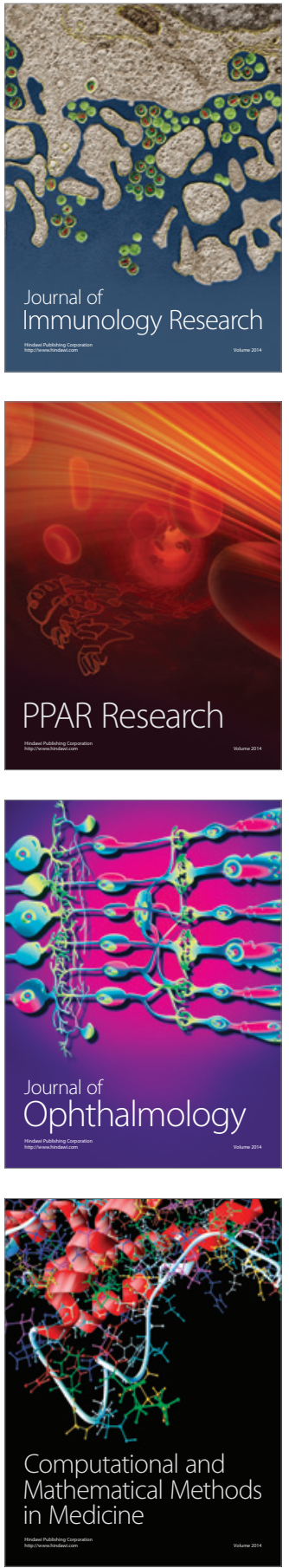

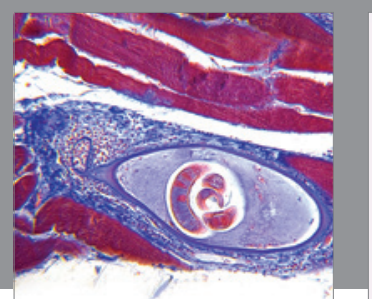

Gastroenterology Research and Practice

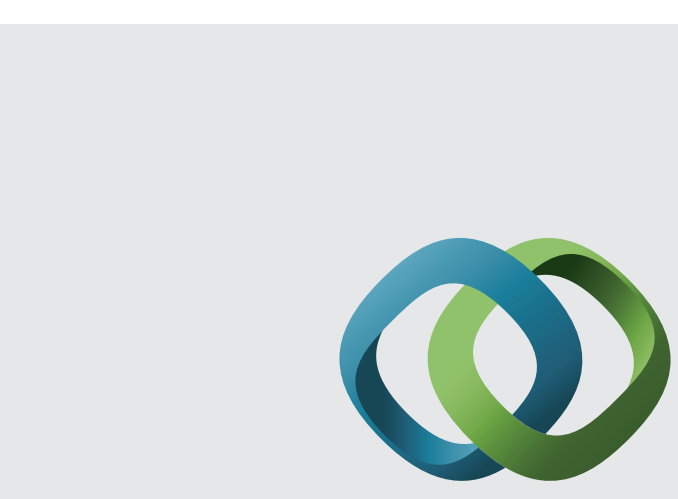

\section{Hindawi}

Submit your manuscripts at

http://www.hindawi.com
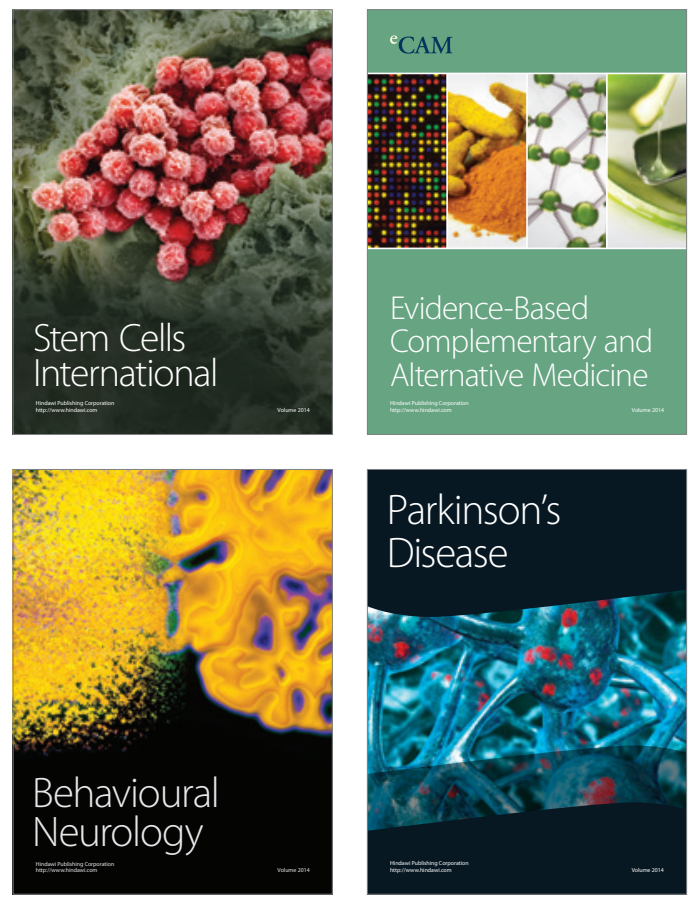
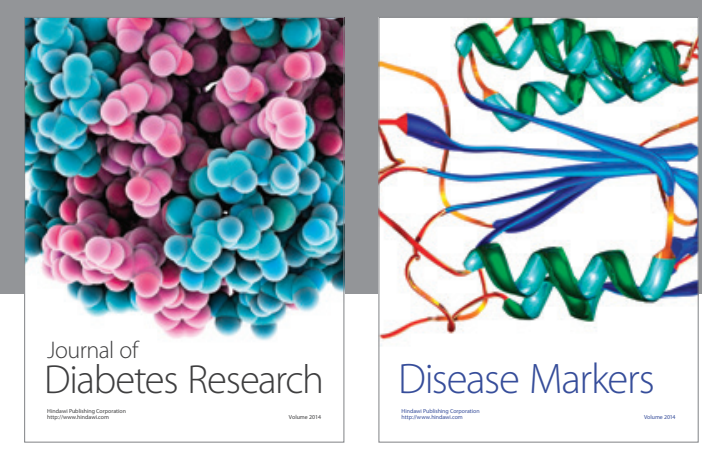

Disease Markers
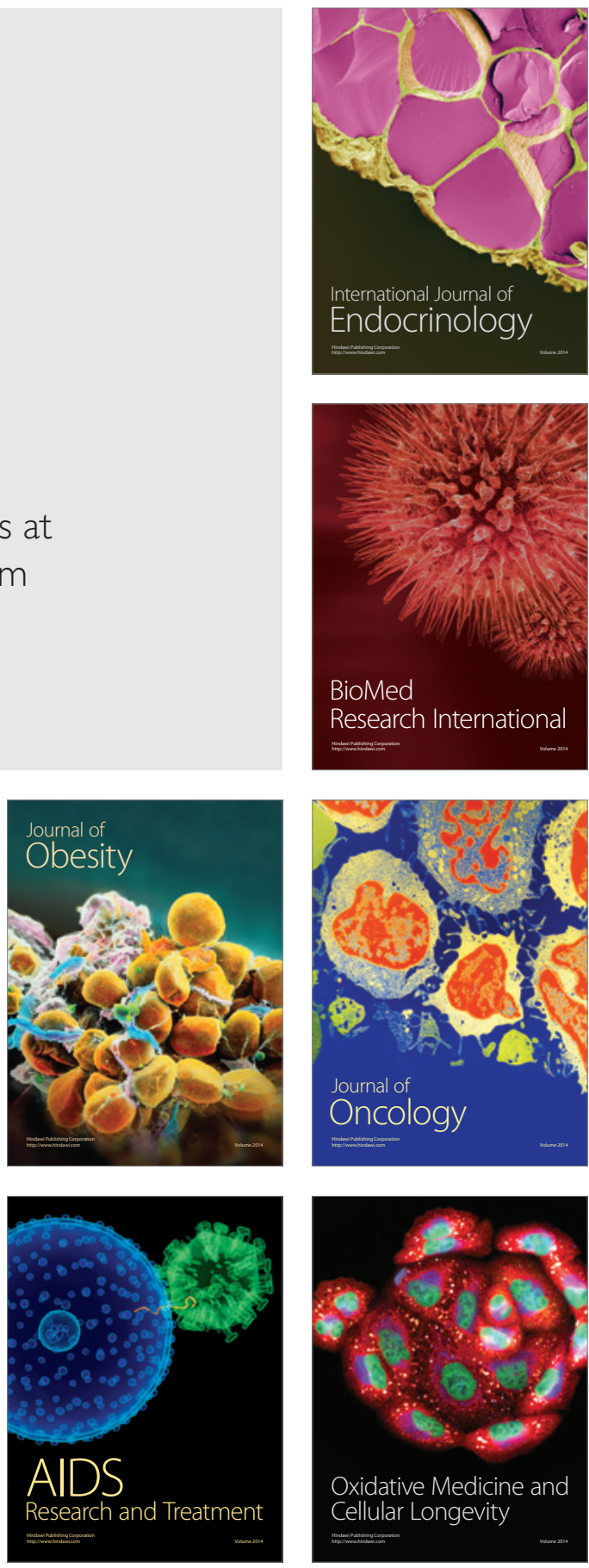